\title{
PREFACE
}

\section{Congratulatory Message}

\section{Kondratiev Gold Medal to Professor Masaaki Hirooka}

\section{Koichi SHIMIZU}

Okayama University

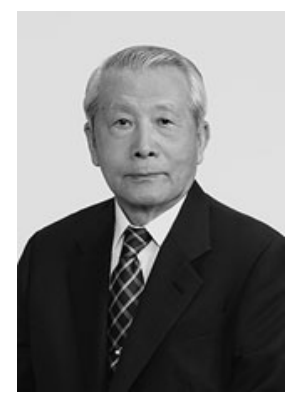

We have great pleasure in reporting that professor Masaaki Hirooka, one of the founders of our Japanese Association for Evolutionary Economics (JAFEE), was awarded the N.D. Kondratiev Gold Medal "for Contribution to the Development of Social Sciences" by the International N.D. Kondratiev Foundation (IKF) and the Russian Academy of Natural Sciences (RANS). As we know, N.D. Kondratiev, known as a proponent of the New Economic Policy (NEP in 1921-1928) supported by Lenin, and famous as the theoretician of the long cycles (Kondratiev cycles), was victim of Stalin's Great Purge because of his theory and policy conflicting with the soviet communist orthodoxy advocating the general crisis of Capitalism. His honor was restored in 1987 by the Soviet Union under the Perestroika regime of Gorbachev. Just after the international conference devoted to the centenary of the birth of N.D. Kondratiev, the IKF was founded in 1992 under the auspices of the RANS, and re-registered in 1999 as "a scientific-social institution with the aim of assisting to studying and advocating of N.D. Kondratiev's scientific heritage". Since 1995, the IKF has been conducting with the RANS the international competitions for N.D. Kondratiev medals: the gold, silver and bronze medals are awarded every three years to Russian and foreign scientists (one for Russian and one for foreign scientists respectively) for outstanding contribution in the development of social sciences. Among the medalists are found Immanuel Wallerstein (gold medal in 2004), Christopher Freeman (silver medal in 2007), Carlotta Perez (silver medal in 2012), and our professor Masaaki Hirooka (gold medal in 2010). Professor Hirooka, after having a long career as a polymer researcher discovering a novel process of alternating copolymerization, has engaged in an economic research at Kobe University and concentrated in clarifying the correlation between technological innovations and economic growth. His main concern has been about demonstrating Schumpeterian hypothesis by the fact that the upswing in Kondratieff's cycles is caused by a cluster of technological innovations. N.D. Kondratieff first disclosed a phenomenon of long business cycles having a time span of 50-60 years in 1925 . He ascribed such economic fluctuation to a cyclic nature of various economic 
phenomena as GNP and other economic aggregates. J. Schumpeter suggested that such business cycles could have a correlation with industrial innovations but failed to justify his hypothesis because he insisted that the innovation cycles should have a time span of ten years. Professor Hirooka first ascribed Kondratieff cycles to the innovation diffusions giving a time span of 50-60 years. This important contribution first appeared in Journal of Evolutionary Economics, 2003, 13, pp. 549-576, and was more comprehensively developed in Innovation Dynamism and Economic Growth: A Nonlinear Perspective, Edward Elgar, 2006 (its Japanese version was published by Nihon Keizai Shimbun Co. in 2003). Further studies were conducted together with Askar Akaev of the RANS and have borne fruits as "A Mathematical Model for Long-term Forecasting of the Dynamics of Innovative Economic Activity", Doklady Akademii Nauk, 2009, Vol. 425, No. 6, pp. 727-732. Through these studies based on thorough examination of dynamic behaviors of industrial innovations since the first Industrial Revolution, Professor Hirooka shows that the nonlinear dynamism of the innovation can be described by a logistic equation; the technological development phase before the innovation diffusion also has such nonlinear nature; and thus innovations induce economic growth. He also demonstrates that further diffusion of innovations builds an infrastructure of the economy across two business cycles. He named this longer diffusion of innovation 'Infratrajectory' caused by trunk innovations, which provokes a techno-economic paradigm change. He further explains the role of financial bubble in the turnover in the long cycle from the upswing to the downswing. These contributions were appreciated by the IKF and RANS at the 2010 international competitions for N.D. Kondratiev medals.
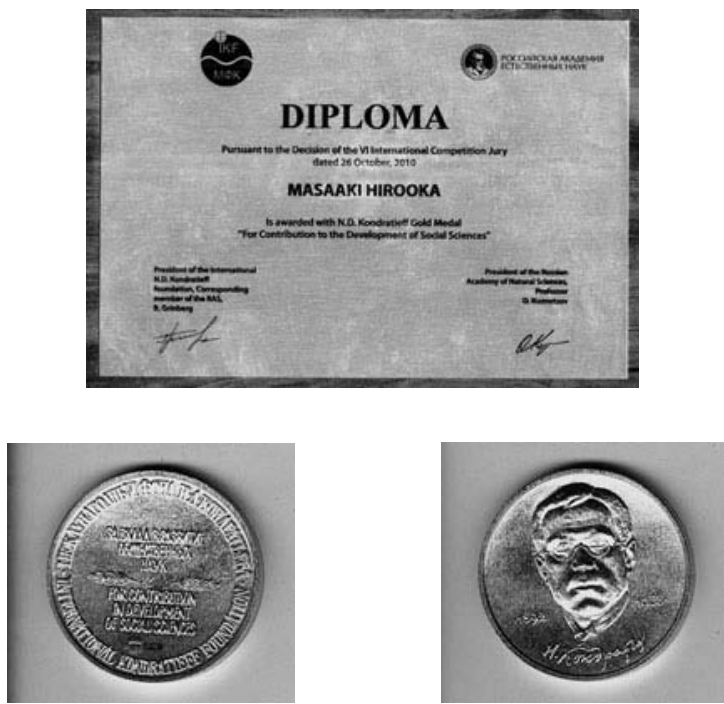